\title{
RESEARCH PAPER \\ EFFECT OF WASTE PLASTICS ADDITION ON THE REDUCTION OF IRON OXIDE BY METALLURGICAL COKE
}

\author{
J. R. Dankwah ${ }^{1}$ and P. Koshy ${ }^{2}$ \\ ${ }^{1}$ Mineral Engineering Department, University of Mines and Technology, Tarkwa, Ghana \\ ${ }^{2}$ School of Materials Science and Engineering, The University of New South Wales, Sydney, \\ Australia
}

\begin{abstract}
This work investigates the effect of waste plastics (high density polyethylene (HDPE)) addition on the production of premium grade iron nuggets from iron oxide using metallurgical coke as reducing agent. Composite pellets were formed from mixtures of iron oxide and carbonaceous materials consisting of coke, HDPE and three blends of coke-HDPE. The iron oxidecarbonaceous material composites were heated very rapidly in a laboratory scale horizontal tube furnace at $1500^{\circ} \mathrm{C}$ in a continuous stream of argon and the off gas was analysed continuously using an online infrared gas analyser and a gas chromatographic analyser. Elemental analyses of samples of the reduced metal were performed chemically for its carbon content and the extent of reduction was calculated based on a mass balance for removable oxygen. The results indicate that blending of coke with HDPE has the beneficial effect of improving the extent of reduction of iron oxide, with the time for complete reduction improving significantly from 600s (Coke) to 330 s for Blends 1 and 2. Blending of coke with $\mathrm{HDPE}$ led to over $20 \%$ reduction in direct carbon dioxide emissions.
\end{abstract}

Keywords: $H D P E$, coke, reduction, carburisation, iron oxide

\section{INTRODUCTION}

In the last few years the demand for high quality scrap steel has soared almost to the point of being scarce in most steel producing countries. This situation (exacerbated by the increasing popularity of electric arc furnaces (EAF) along with the emergence of ultra-high productivity (UHP) furnaces calls for alternative iron materials (AI), as substitute for scrap.
Current and emerging technologies (e.g. HIQIP, FASTMET, ITmk3, etc.) utilised in the production of AIs are based on natural gas or low quality coals as reductants for iron oxide reduction (Sawa et al., 2001). While it is impossible to expand gas-based AI processes due to limited and localised supply of natural gas, the reduced iron in the coal-based processes con- 
tains a relatively high slag content from coal ash and gangue, which results in increased lime addition and electrode consumption (Sawa et al., 2001). Besides, some steel producing countries have limited or no sources of coal or natural gas, necessitating the need for the development of novel processes based on local energy conditions and raw materials.

Ghana has three main iron ore deposits of potential industrial and commercial importance, namely the Shieni sedimentary, Opon-Mansi lateritic and the Pudotitaniferous-magnetiferous deposits from which these AIs could be produced directly to feed its existing steelmaking industries.

One potential group of materials that could wholly or partially replace coal and/or natural gas is postconsumer plastics. The generation of this category of waste stream has increased tremendously in recent years because the annual consumption rate of plastic materials has seen a consistent increase from around 5 million tonnes in the 1950's to nearly 100 million tonnes by 2005 (Recycling Survey, 2005).

The use of waste polymeric materials as chemical feedstock in iron and steelmaking has not been widely investigated. Moreover, most of the research on the reduction of iron oxides has focused on the use of carbon (in the form of graphite or metallurgical coke) as a reducing agent. Polymers like polyethylene contain both carbon and hydrogen and their thermal decomposition at high temperatures generates significant amounts of methane and hydrogen, which are known reductants of metal oxides (Nishioka et al., 2007; Dankwah et al., 2012, Dankwah et al., 2014; Dankwa and Koshy, 2013, Dankwa and Koshy, 2014).

In the present work, the potential for producing carburised nuggets of metallic iron from hematite using HDPE and its blends with coke as reducing and carburising agents is investigated under inert atmosphere in a custom made horizontal tube furnace. Discussions on the effect of HDPE addition on the extent of reduction, carburisation and gas emissions are highlighted as well.

\section{MATERIALS AND METHODS}

Materials and preparation

Metallurgical coke (obtained from One Steel Sydney Mill, Australia) and its blends with granulated HDPE (obtained from Qenos Pty. Ltd., Victoria, Australia) were employed in this study as carbonaceous materials (Table. 1). The chemical composition (wt \%) of the samples and the ash analysis are given in Tables 2- 3 . Pulverised reagent grade iron oxide assaying 96.89\% $\mathrm{Fe}_{2} \mathrm{O}_{3}$ was obtained from Ajax Fine Chem Pty Ltd, Taren Point, NSW, Australia; its composition was determined by XRF analysis and the result is given in Table 4. Samples of coke were ground and sieved to particle size in the range of $-470+450 \mu \mathrm{m}$ while samples of granulated HDPE were crushed to smaller sizes by using a cutting mill "Pulverisette 15" (Fritsch GmbH, Idar-Oberstein, Germany). By means of a sieve insert with $0.5 \mathrm{~mm}$ trapezoidal perforations in the cutting mill, a particle size $-470+450 \mu \mathrm{m}$, similar to that of coke was obtained. Blends of coke/HDPE were prepared in three different proportions and along with raw coke and raw HDPE, five reductants were utilised for this investigation. Fixed masses of iron oxide $(\sim 1.86 \mathrm{~g})$ were subsequently mixed with the carbonaceous reductants ( $30 \mathrm{wt}$. \%) and compacted in a die to produce cylindrical pellets $(\sim 14 \mathrm{~mm}$ thick and $15 \mathrm{~mm}$ diameter $)$ by applying a load of 7.5 tonnes for 120 s in a hydraulic press.

\section{Methods \\ Thermal decomposition studies}

The hydrocarbonaceous materials (HDPE and coke-HDPE) were mixed thoroughly with alumina powder $(-150 \mu \mathrm{m})$ and cylindrical pellets were formed from the resulting mixture by applying a load of 7.5 tonnes for $60 \mathrm{~s}$ in a hydraulic press. The use of alumina powder was to slow down the decomposition process (to enable gas measurements by the IR analyser) as well as mimic the reduction environment through the cylindrical pellets. The alumina 
Table 1: Blend compositions of the different carbonaceous materials utilised in this study

\begin{tabular}{lccccc}
\hline Carbonaceous material & Coke & Blend 1 & Blend 2 & Blend 3 & HDPE \\
\hline Coke $($ wt \%) & 100 & 90 & 80 & 70 & 0 \\
HDPE (wt \%) & 0 & 10 & 20 & 30 & 100 \\
\hline
\end{tabular}

Table 2: Chemical composition of coke and HDPE utilised in current study

\begin{tabular}{lcccccccc}
\hline Component & Moisture & $\begin{array}{l}\text { Volatile } \\
\text { Matter }\end{array}$ & Ash & $\begin{array}{l}\text { Total } \\
\text { Carbon }\end{array}$ & $\begin{array}{l}\text { Fixed } \\
\text { Carbon }\end{array}$ & Hydrogen & Sulphur & Nitrogen \\
\hline Coke (wt \%) & 1.30 & 3.0 & $\begin{array}{c}18.3 \\
0\end{array}$ & 78.70 & 77.36 & - & 0.32 & 1.21 \\
HDPE (wt \%) & - & 99.4 & 0.6 & 85.5 & - & 14.2 & 0.3 & - \\
\hline
\end{tabular}

Table 3: Ash analysis of coke used in the study

\begin{tabular}{lcccccccccc}
\hline Component & $\mathbf{S i O}_{\mathbf{2}}$ & $\mathbf{F e}_{\mathbf{2}} \mathbf{O}_{\mathbf{3}}$ & $\mathbf{A l}_{\mathbf{2}} \mathbf{O}_{\mathbf{3}}$ & $\mathbf{T i O}_{\mathbf{2}}$ & $\mathbf{P}_{\mathbf{2}} \mathbf{O}_{\mathbf{5}}$ & $\mathbf{C a O}$ & $\mathbf{M g O}$ & $\mathbf{N a}_{\mathbf{2}} \mathbf{O}$ & $\mathbf{K}_{\mathbf{2}} \mathbf{O}$ & $\mathbf{S O}_{\mathbf{3}}$ \\
\hline Composition (wt \%) & 50.7 & 4.8 & 36.0 & 1.4 & 1.6 & 3.3 & 0.94 & 0.39 & 0.53 & 0.39 \\
\hline
\end{tabular}

Table 4: Chemical composition (XRF) of iron ore (wt \%)

\begin{tabular}{lcccccccc}
\hline Component & $\mathbf{F e}_{\mathbf{2}} \mathbf{O}_{\mathbf{3}}$ & $\mathbf{S i O}_{\mathbf{2}}$ & $\mathbf{A l}_{\mathbf{2}} \mathbf{O}_{\mathbf{3}}$ & $\mathbf{C a O}$ & $\mathbf{M n O}$ & $\mathbf{Z n O}$ & $\mathbf{T i O}_{\mathbf{2}}$ & $\mathbf{S O}_{\mathbf{3}}$ \\
\hline Composition (wt \%) & 96.89 & 0.445 & - & 0.0225 & 0.020 & 0.0115 & 0.134 & 0.257 \\
\hline
\end{tabular}

powder acted as a blank medium, since its reduction will be difficult at the selected temperature.

\section{Reduction studies}

A LECO ${ }^{\mathrm{TM}}$ crucible was selected as the sample container in a custom-made horizontal tube furnace (HTF) for the reduction studies (Fig. $1)$.

The electrically heated HTF tube has an inside diameter of $50 \mathrm{~mm}$ and was fabricated from double-walled, vacuum-insulated stainless steel tubes fitted with a cooling fan to dissipate heat. It is a micro scale reactor and is suitable for temperatures up to $1700{ }^{\circ} \mathrm{C}$.

The furnace tube was controlled by a digital mass flow meter throughout the experiment, while a high-resolution coloured chargecoupled device (CCD) camera provided with IRIS TV zoom lens was used to capture the live in-situ phenomena in the furnace. The melting of the composite pellet marked the beginning of contact time. The output from the camera was channelled to a TV monitor and a video cass- 


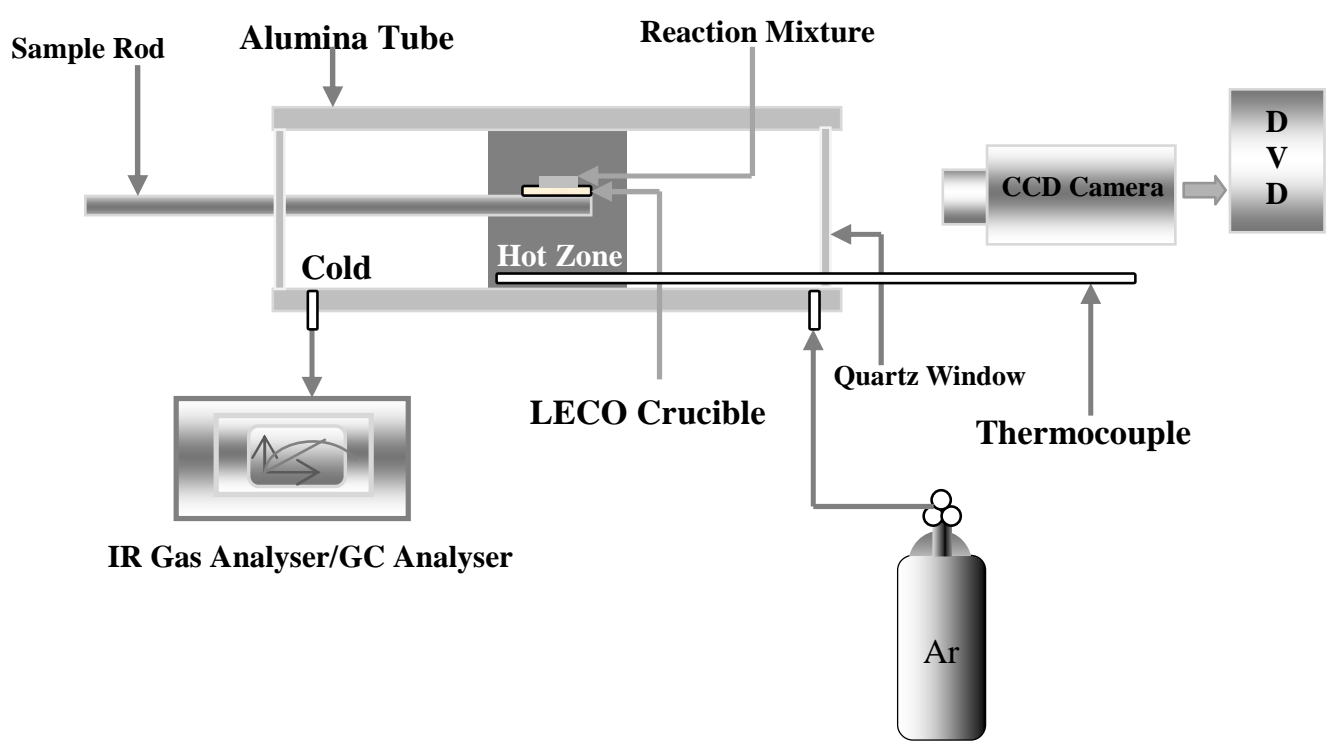

Fig. 1: Schematic representation of the horizontal furnace

ette recorder (VCR) to record the entire process as a function of time. An infrared gas analyser was attached to this system to monitor $\mathrm{CH}_{4}, \mathrm{CO}$ and $\mathrm{CO}_{2}$ gases produced by the reduction reaction and the results were recorded in a datalogging computer.

The sample assembly was placed in the furnace, which was purged continuously with argon (of $99.995 \%$ purity and flow rate $1 \mathrm{~L} / \mathrm{min}$ ) to ensure inert conditions.

After the furnace had attained the desired hot zone temperature $\left(1500^{\circ} \mathrm{C}\right)$, the sample was pushed into the reaction hot zone and gases were monitored for 1200s. This time was selected since initial trials showed no significant changes in gas composition or degree of reduction beyond 1200s.

Reacted carbonaceous material/iron oxide samples were quenched by rapidly withdrawing the tray from the reaction zone into the cold zone of the furnace. Particles of reduced iron metal, which were clearly visible to the naked eye, were removed by a magnetic screw driver and its content was determined by the following chemical analysis methods:

- $\quad \mathrm{LECO}^{\mathrm{TM}} \mathrm{C} / \mathrm{S}$ analysis for its $\mathrm{C}$ and $\mathrm{S}$ contents and

- LECO $^{\mathrm{TM}}$ Oxygen analyser for its O content.

\section{RESULTS AND DISCUSSION}

Thermal decomposition behaviour of HDPE The thermal decomposition behaviour of HDPE at $1500^{\circ} \mathrm{C}$ is illustrated in Figs 2 and 3. Two distinct features are noticeable from the thermal decomposition of HDPE:

- The generation of $\mathrm{CH}_{4}$

- The generation of hydrogen, indicated by the sharp peak in Fig. 3. 
Thus thermal decomposition of HDPE generates the gaseous reducing species $\mathrm{CH}_{4}$ and $\mathrm{H}_{2}$ into the reaction environment; this may enhance the overall reduction process.
NATURE OF REDUCED METAL

Nearly spherical samples of reduced metal were obtained for all blend proportions and the result for HDPE as the reducing agent is shown in

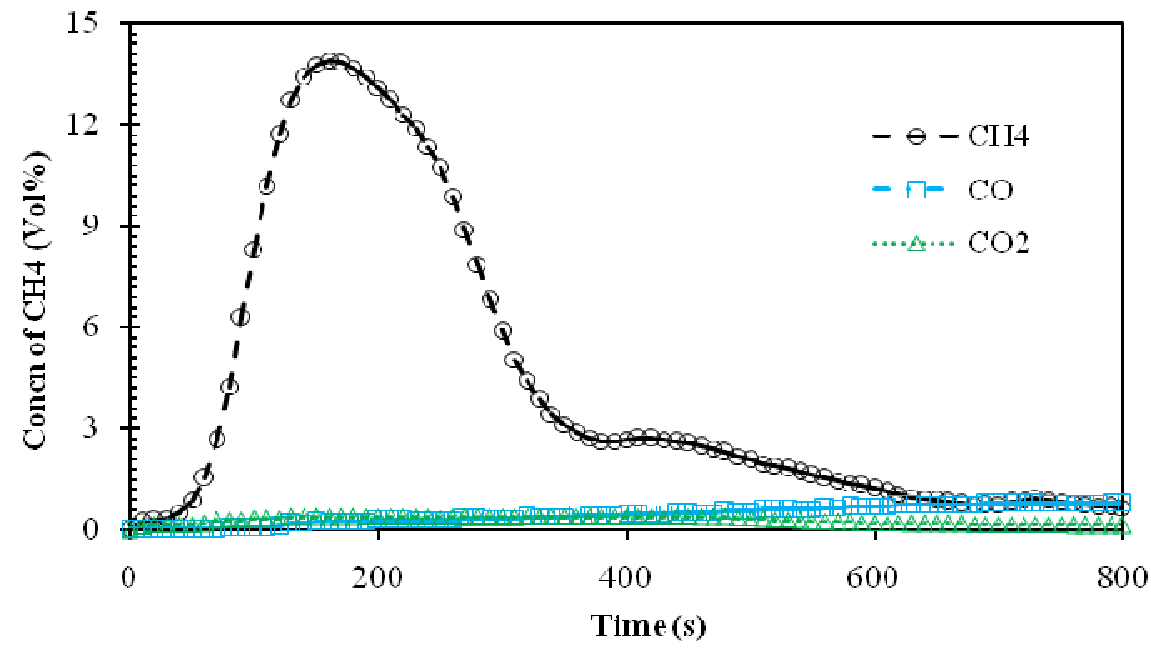

Fig. 2: Gas generation behaviour during the thermal decomposition of HDPE from a HDPEalumina compact

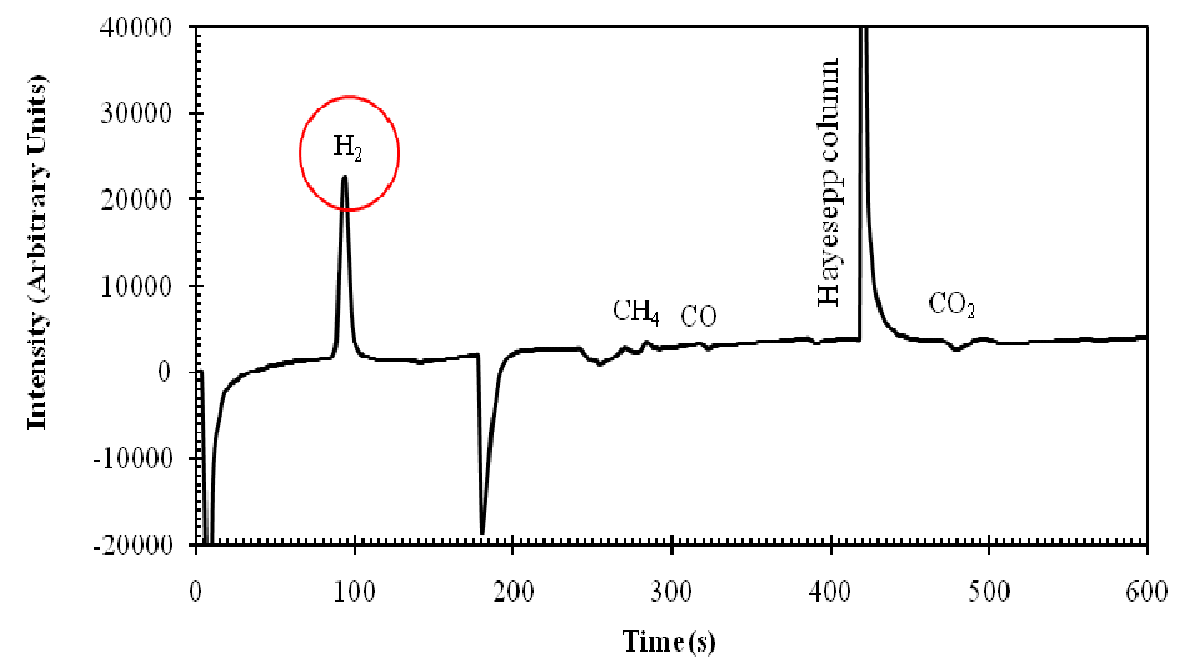

Fig. 3: Gas chromatogram obtained after 60s of heating HDPE-alumina compact 
Fig. 4. The vigorous nature of the reaction is apparent from Fig. 4, where droplets of metallic iron are seen deposited across the entire volume of the crucible.

The conventional reductant for iron oxide reduction in industry is typically metallurgical coke and other forms of carbon, hydrogen and natural gas. Even without blending with any of the conventional reductants, this investigation has demonstrated that the heaps of waste plastics currently stockpiled on landfills or littered on the streets of various municipalities and metropolis could be diverted into the ironmaking industry as important chemical feedstock.

\section{IR GAS ANALYSES}

The contents of $\mathrm{CO}$ and $\mathrm{CO}_{2}$ in the off-gas were measured continuously by an infrared (IR) gas analyser from which the rates of gas evolution $(\mu \mathrm{mol} / \mathrm{s} . \mathrm{g}-\mathrm{Fe})$ were calculated for each carbonaceous blend. The results are shown in Fig. 5. The rates of evolution of $\mathrm{CO}$ and $\mathrm{CO}_{2}$ increased slowly for the first 200 seconds for HDPE (Fig. 5a), followed by a sharp rise, attaining maximum values of 154.4 and
$16.6 \mu \mathrm{mol} / \mathrm{s} . \mathrm{g}-\mathrm{Fe}$ after about $230 \mathrm{~s}$ and $220 \mathrm{~s}$, respectively. Fig. 5b illustrates the gas generation behaviour of coke; active gas generation by coke commences almost immediately after pushing the tray into the hot zone and it attains maximum values of 108.8 and $30.0 \mu \mathrm{mol} / \mathrm{s} . \mathrm{g}-\mathrm{Fe}$ after about $150 \mathrm{~s}$ and $70 \mathrm{~s}$ for $\mathrm{CO}$ and $\mathrm{CO}_{2}$, respectively. $\mathrm{CO}_{2}$ generation by coke is higher compared to HDPE, which has almost negligible $\mathrm{CO}_{2}$ generation. Gas generation by HDPEcoke blends as in Figs. 5 (c-e) commenced earlier than HDPE but later than coke.

It is apparent from Fig. 5 that all the blends showed lower $\mathrm{CO}_{2}$ evolution compared to coke and that $\mathrm{CO}_{2}$ evolution generally decreased as the amount of HDPE blended with coke increased. For all the reductants, $\mathrm{CO}_{2}$ and/or $\mathrm{H}_{2} \mathrm{O}$ evolution are significantly lower than $\mathrm{CO}$. The relatively lower values recorded for $\mathrm{CO}_{2} / \mathrm{H}_{2} \mathrm{O}$ compared to $\mathrm{CO}$ may be an indication of direct reduction of $\mathrm{Fe}_{2} \mathrm{O}_{3}$ by $\mathrm{C}$ or a dominant carbon gasification reaction by $\mathrm{CO}_{2}$ (Boudouard reaction) and/or $\mathrm{H}_{2} \mathrm{O}$ (oxidation of $\mathrm{C}$ by $\mathrm{H}_{2} \mathrm{O}$ ). These two reactions are highly endothermic and occur above $1000^{\circ} \mathrm{C}$ (Biswas, 1981), a tem-

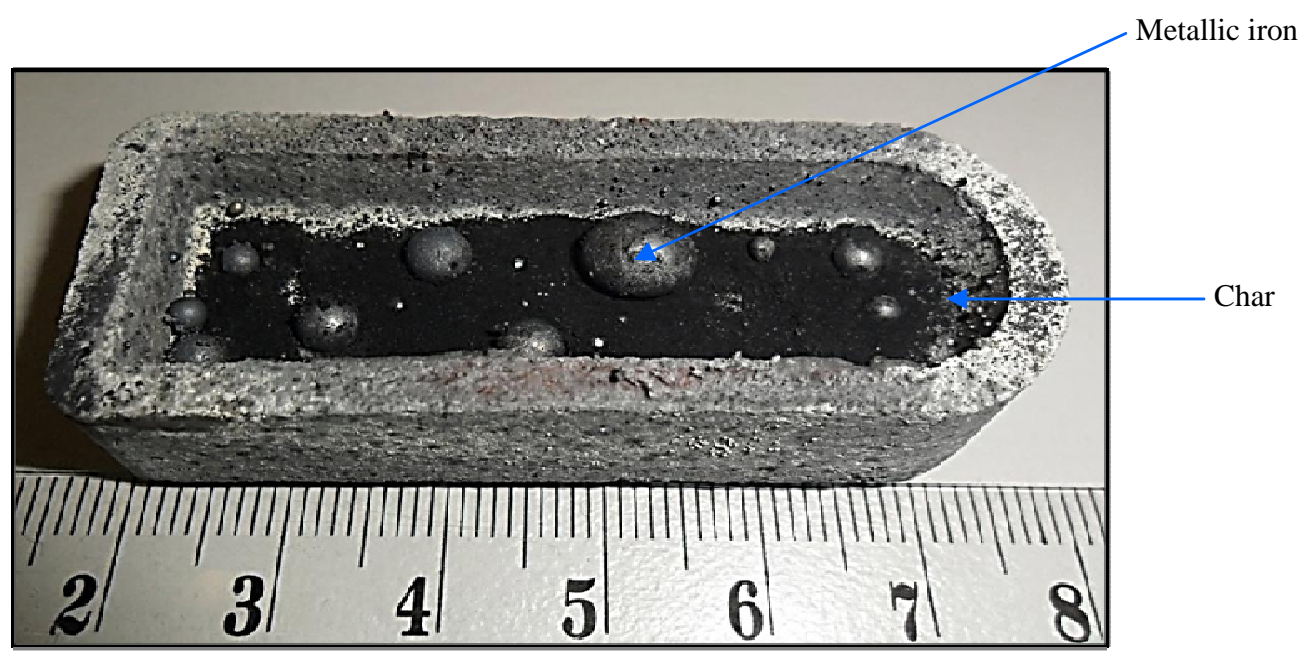

Fig. 4: Droplets of metallic iron and char obtained after reduction of red mud by HDPE (600s of reaction) 
perature range that is within the experimental temperature of the current investigation. Another possible reaction is the direct reduction of $\mathrm{Fe}_{2} \mathrm{O}_{3}$ by $\mathrm{CH}_{4}$, which was the predominant hydrocarbon gas detected in the off-gas in the initial stages of the reduction process.

$3 \mathrm{CH}_{4}+\mathrm{Fe}_{2} \mathrm{O}_{3}=2 \mathrm{Fe}+6 \mathrm{H}_{2}+3 \mathrm{CO}$

Fraction reacted as a function of time

The change in fraction reacted, $f$, was plotted as a function of time for coke, HDPE, and the blends (Fig. 6). In the first four minutes of reduction, no noticeable difference is observed between the blends on one hand and coke on the other. However, reduction by coke slows down significantly after this period. A possible reason could be the high ash content $(18.3 \mathrm{wt}$ $\%$ ) of the coke utilised for this investigation; this could have coated the surface of the partially reduced metal and consequently inhibit further reaction.

From Fig. 6, the time for complete reduction of iron oxide was $600,580,330,330$ and 340 s for Coke, HDPE, Blend 1, Blend 2, and Blend 3, respectively, as the carbonaceous reductant. The times recorded in this investigation

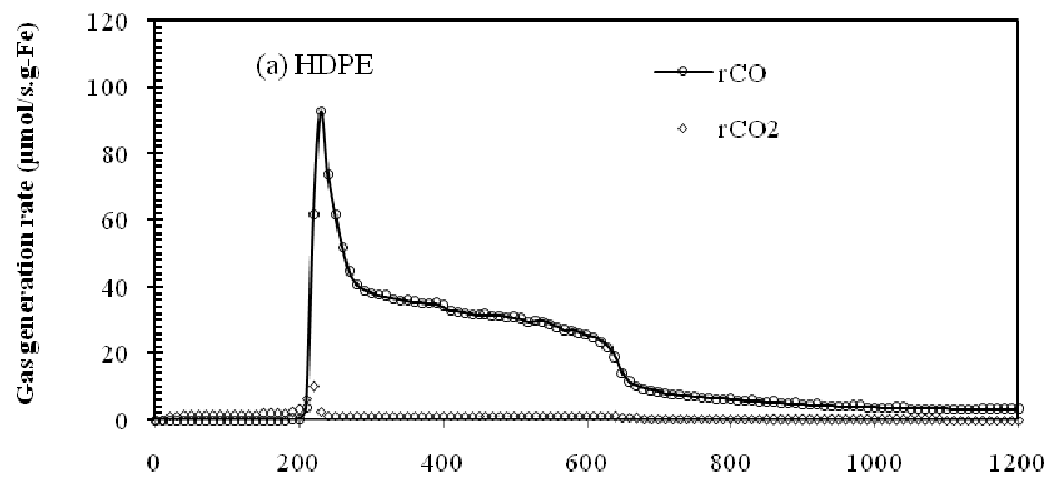

(a)

Time (s)

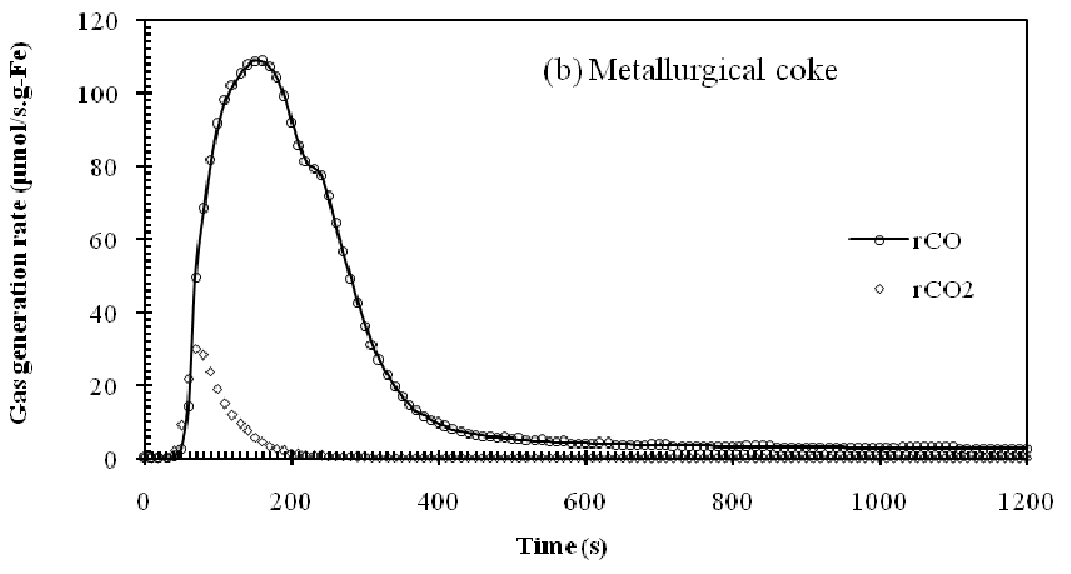

(b) 


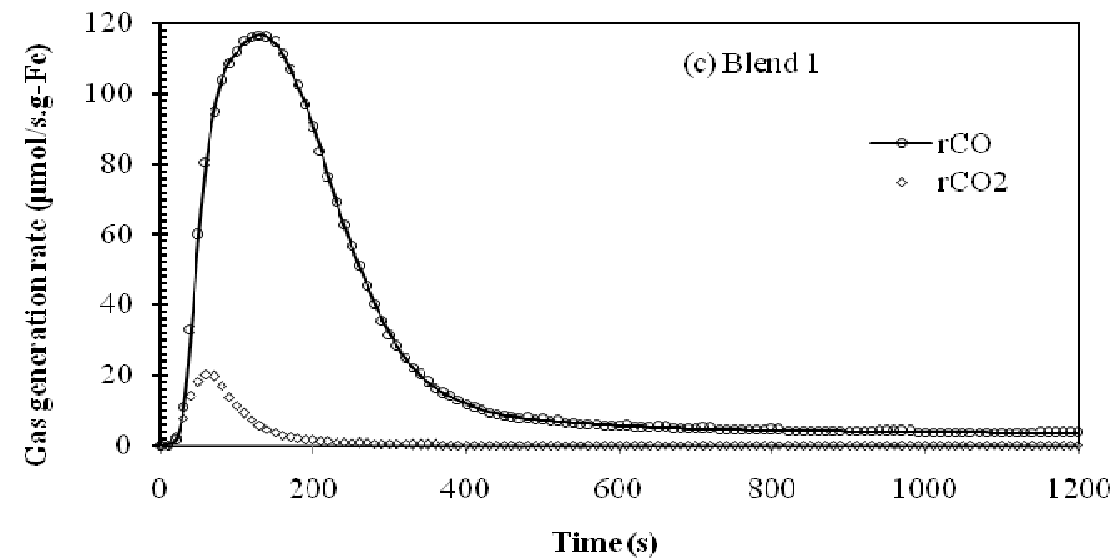

(c)

Time(s)

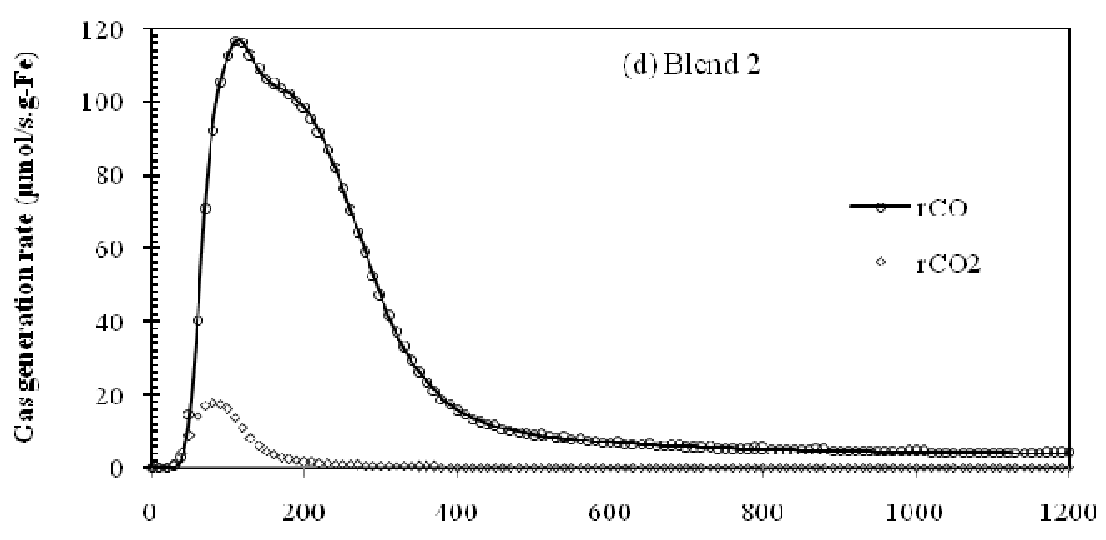

(d)

Time (s)

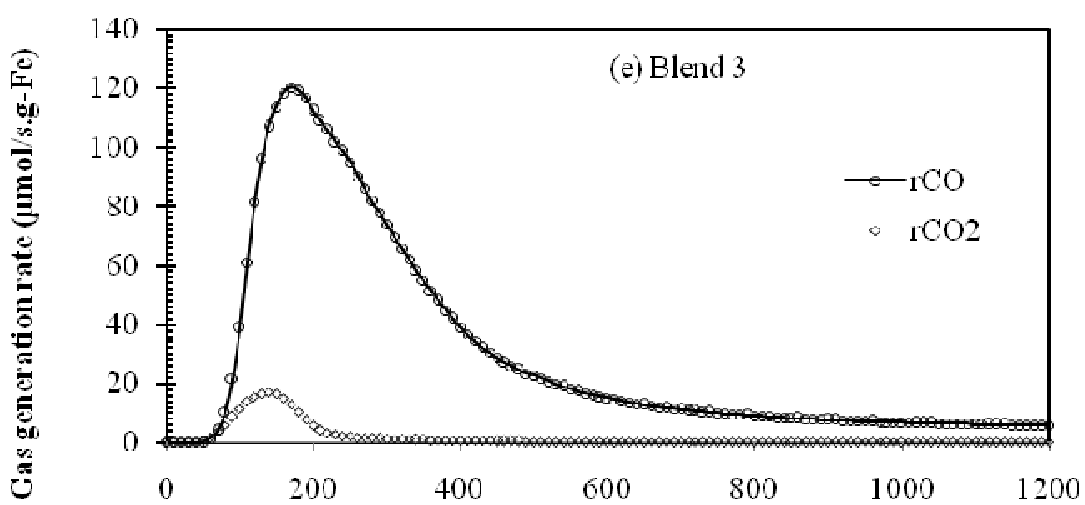

(e)

Time(s)

Fig. 5: Change in the rate of generation of $\mathrm{CO}$ and $\mathrm{CO}_{2}$ with time for a) HDPE, b) Coke, c) Blend 1, d) Blend 2 and e) Blend 3 


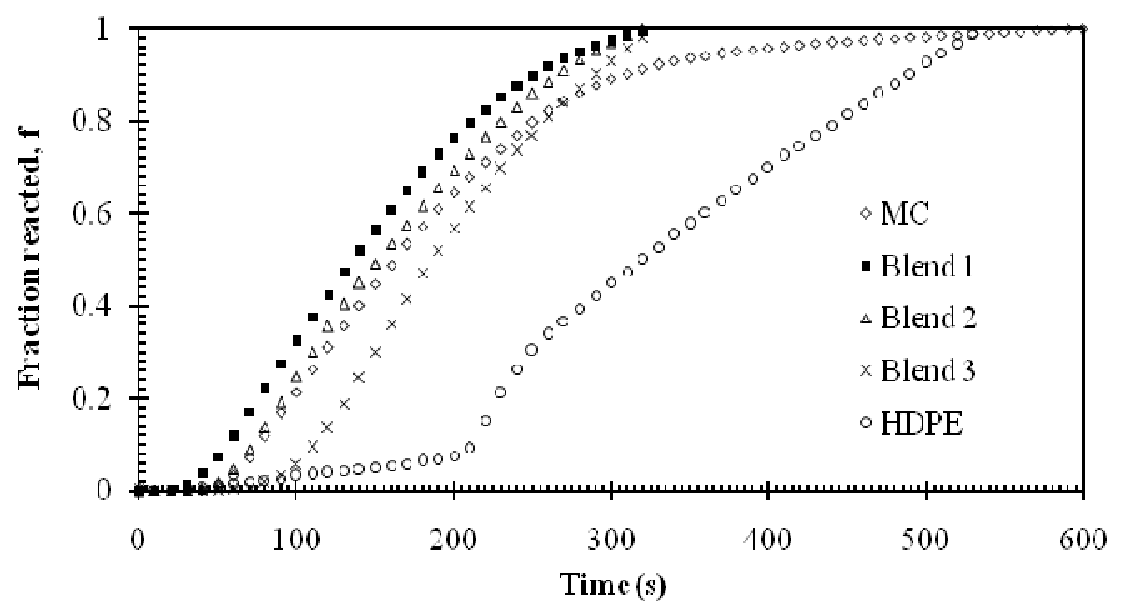

Fig. 6: Change in fraction reacted, $f$, with time for each carbonaceous reductant

agree with the observation by Kikuchi et al. (2010) that composite pellets of iron oxidecarbonaceous material could be reduced within 600s. Although HDPE has little or no fixed carbon, $\mathrm{CH}_{4}$ generated in the initial stages of heating was converted to nascent carbon and hydrogen and the reaction was catalysed by freshly produced metallic iron, as observed by Murakami and Kasai (2011). Blending of coke with HDPE therefore promotes the generation of hydrogen in the reaction environment. Hydrogen gas, apart from being a faster reducing agent than both carbon monoxide and solid carbon (Sohn and Fruehan, 2005; OnoNakazato et al., 2003), also enhances the rate of reduction of iron oxides by carbon monoxide (Ono-Nakazato et al., 2003)when it is added to a reaction system containing the latter.

Peaks of hydrogen were detected in the off gas when the iron oxide was reduced by HDPE and the blends. No such peaks were visible when coke was used as the reductant (Fig.7)

As observed by Donskoi et al. (2003), $\mathrm{CO}_{2}$ and $\mathrm{H}_{2} \mathrm{O}$ produced from the reduction of iron oxide gasify any available carbon at high temperatures to regenerate $\mathrm{CO}$ and $\mathrm{H}_{2}$. Accordingly, a series of cyclic reactions is set up as $\mathrm{CO}$ and $\mathrm{H}_{2}$ (products of the carbon gasification reactions) in turn partially react with any unreduced iron oxide and further reactions continue (Donskoi et al., 2003; Shi et al., 2008).These cyclic reactions persist until all the iron oxide has been reduced to metallic iron, provided there is enough carbon in the system (Shi et al., 2008) as is the case in this investigation. It is thus clear that hydrogen along with some fixed carbon in a carbonaceous material is essential to initiate and maintain these cyclic reactions to obtain a high rate of reduction. This essential requirement is met when coke (77.36wt.\% fixed carbon) is blended with $\operatorname{HDPE}(\sim 14.2 \mathrm{wt}$. $\left.\% \mathrm{H}_{2}\right)$ and it explains why the blends generallyperform better than either coke alone or HDPE alone.

\section{CONTENT OF CARBON IN THE RE-} DUCED METAL

Carburisation of the reduced metal is required for lowering its melting temperature and obtaining a melt and slag separation at molten 
(a)
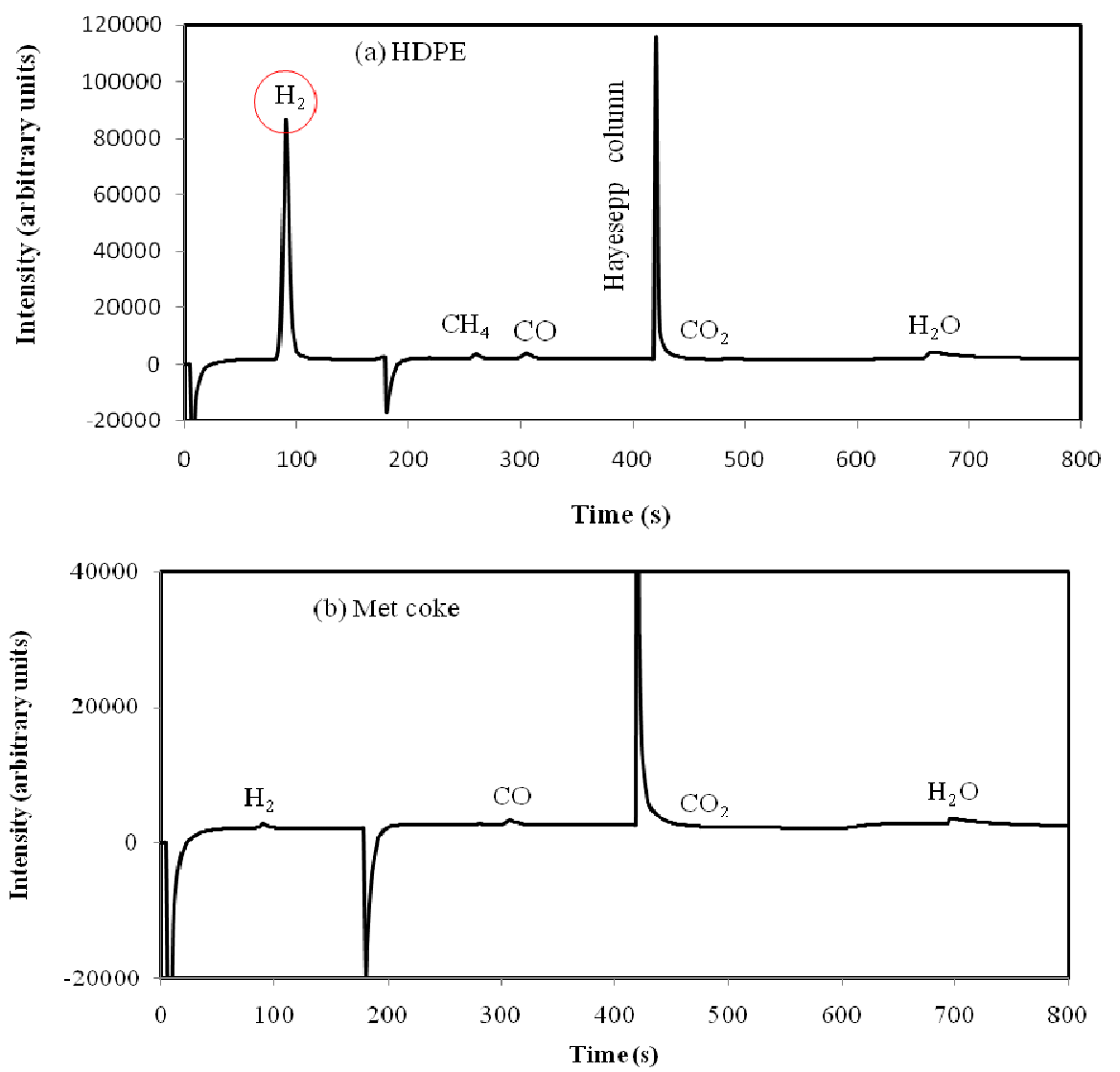

Fig. 7: Gas chromatogram obtained after reduction of iron oxide by (a) HDPE and (b) Coke for $60 \mathrm{~s}$ at $1500^{\circ} \mathrm{C}$

state. Besides, solute carbon has been documented to contribute to slag foaming if the reduced metal is subsequently used as iron feedstock for electric arc furnace steelmaking (Jones, 2007).

The content of carbon in the reduced metal was determined using a LECO Carbon/Sulphur analyser (model CS 230, LECO Corporation, Michigan, USA); the results are shown in Fig. 8. The highest level of carburisation was observed for Blend 3 (2.964wt\%). Carburisation is lowest for $\operatorname{HDPE}(1.335 \mathrm{wt} \%)$, followed by coke $(1.643 \mathrm{wt} \%)$, Blend 2 (1.880wt \%) and
Blend 1 (1.943 wt \%). Blending resulted in improved carburisation, as all the blends showed higher levels of carburisation than coke or HDPE. Dankwah et al.(2012) attributed increased levels of carburisation to the presence of a hydrogen environment along with the fixed carbon content of a carbonaceous reductant. In the absence of hydrogen the metal is carburised mainly by reaction 2. (Fruehan, 1973a; Fruehan 1973b):

$2 \mathrm{CO}_{(\mathrm{g})}=\mathrm{CO}_{2(\mathrm{~g})}+\underline{\mathrm{C}}($ in $\mathrm{Fe})$

In a $\mathrm{CO}-\mathrm{H}_{2}-\mathrm{CH}_{4}$ environment (due to thermal/ catalytic cracking and gasification of the 
polymer) the reduced metal is carburised via three parallel reactions, which consist of reaction 2 and the following (Fruehan, 1973a; Fruehan 1973b):

$\mathrm{H}_{2(\mathrm{~g})}+\mathrm{CO}_{(\mathrm{g})}=\mathrm{H}_{2} \mathrm{O}_{(\mathrm{g})}+\underline{\mathrm{C}}($ in Fe$)$

$\mathrm{CH}_{4(\mathrm{~g})}=\underline{\mathrm{C}}($ in $\mathrm{Fe})+2 \mathrm{H}_{2(\mathrm{~g})}$

Fruehan (1973a) calculated an apparent rate constant for reaction 3 that was over five times higher than that for reaction 2. Kaspersma and Shay (1980) determined the rate constant for carburisation by reaction 3 to be sixteen times greater than that by reaction 2 and twenty two times that by reaction 4. Karabelchtchikova (1997)calculated a rate constant for reaction 3 that was 30 and 100 times faster than reactions 2 and 4, respectively. It is apparent from the forgoing discussions that carburization through reaction4 is negligibly small and can be ignored. Additionally, in a hydrogen environment, carburisation through reaction 2 is negligibly small, compared to that through reaction 3. While HDPE had no fixed carbon, coke had no hydrogen; the blends satisfy the condition for improved carburisation (hydrogen from the HDPE (14.2 wt \%) and a relatively high level of fixed carbon from coke (77.36 wt \%).

The metallic iron produced was spherical in each case (Fig. 4), indicating that it was formed from the liquid state. The experimental temperature of $1500{ }^{\circ} \mathrm{C}$ is below the melting point of iron $\left(1536{ }^{\circ} \mathrm{C}\right)$; the near perfect spherical shape of the iron nuggets as observed in this investigation is only possible for higher carburisation or the presence of further alloying elements in the reduced metal. The level of carburisation achieved (including pure HDPE) is sufficiently high to justify the observation of near perfect spherical shape. Dankwah et al. (2012) observed that the time taken for complete melting of pellets decreased as the proportion of the polymer in the blend increased. No significant difference in the time for complete melting was observed in this investigation for the different blends used (melting time was 150 -250s). Accordingly, it can be concluded that the pellets were first reduced to form solid iron, followed by carburisation, melting and agglomeration of smaller particles into bigger lumps.

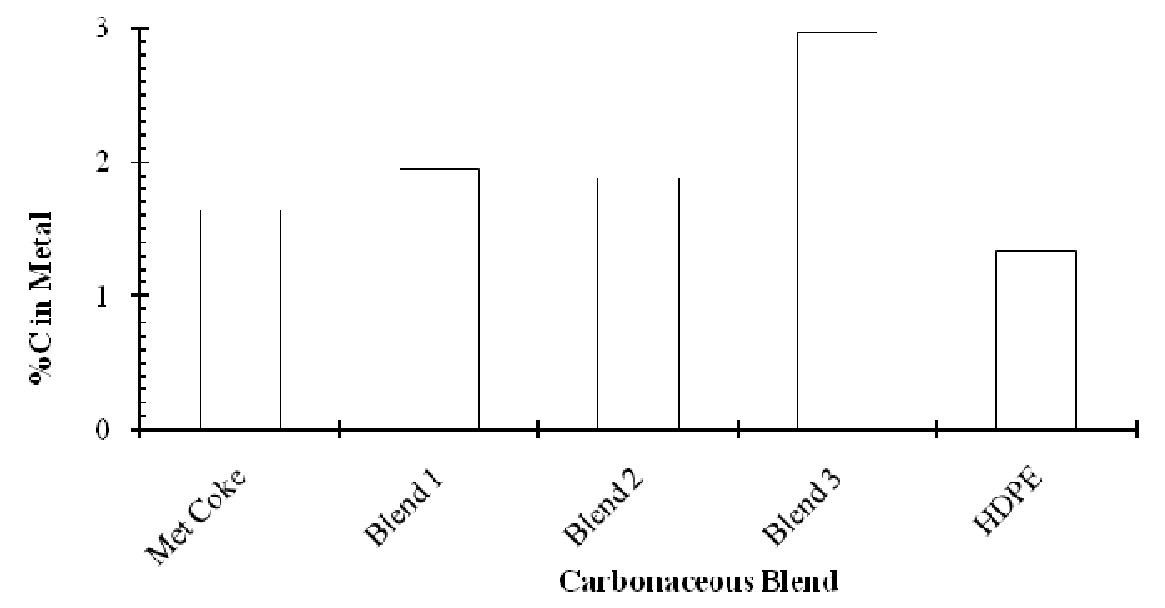

Fig. 8: Carburisation of the metal formed after reduction of iron oxide by each carbonaceous reductant at $1500{ }^{\circ} \mathrm{C}$ 
Environmental considerations: $\mathrm{Co}_{2}$ emissions The rate and relative amounts of $\mathrm{CO}_{2}$ evolved after complete reduction of the iron oxide by each carbonaceous reductant replotted in Figs. 9 and 10 , receptively. The reduction in $\mathrm{CO}_{2}$ emissions over coke by the use of HDPE and each of the blends is plotted in Fig. 11. It is clear from Figs. 9 and 10 that the highest amount of $\mathrm{CO}_{2}$ was produced from the reactions involving coke while the lowest value was recorded for HDPE. From Fig. 11, over 20\% reduction in $\mathrm{CO}_{2}$ emissions can be achieved by using HDPE or Blend 2 as a reductant instead of coke. The observed decrease in $\mathrm{CO}_{2}$ emis-

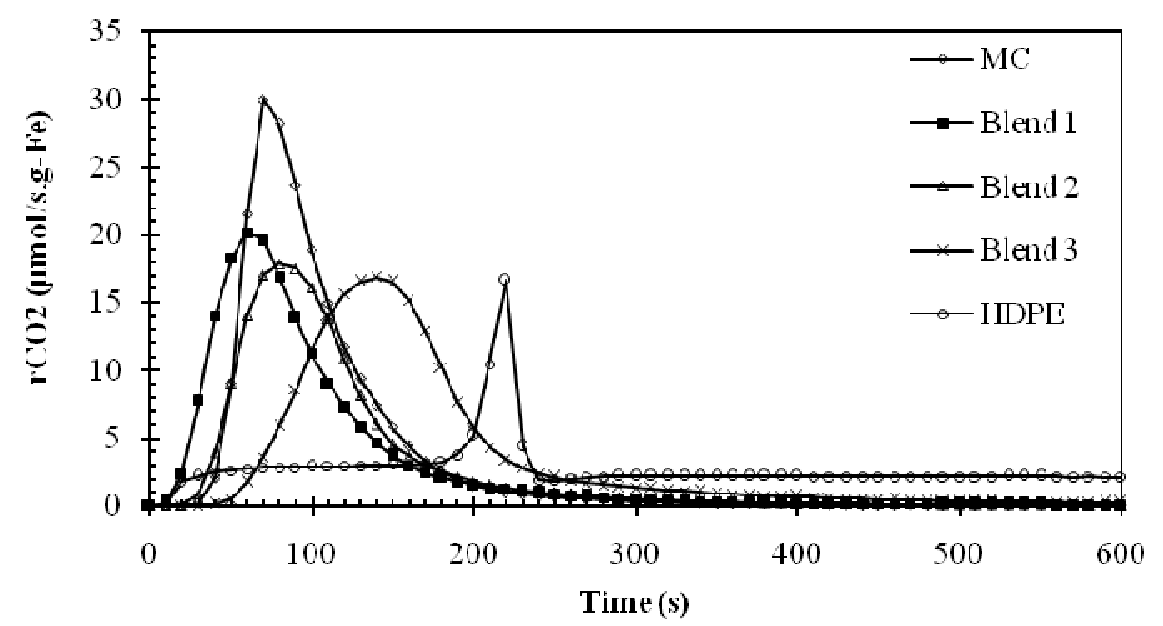

Fig. 9: Concentration of $\mathrm{CO}_{2}$ generated by reactions of the hematite with each carbonaceous reductant

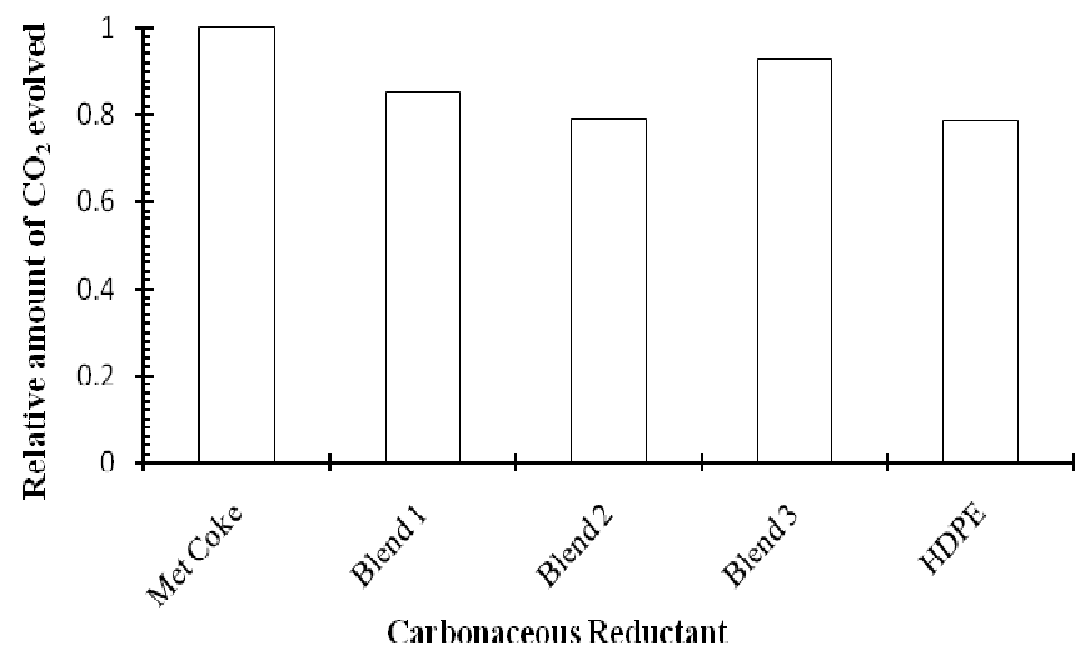

Fig. 10: Relative amounts of $\mathrm{CO}_{2}$ generated after reduction 


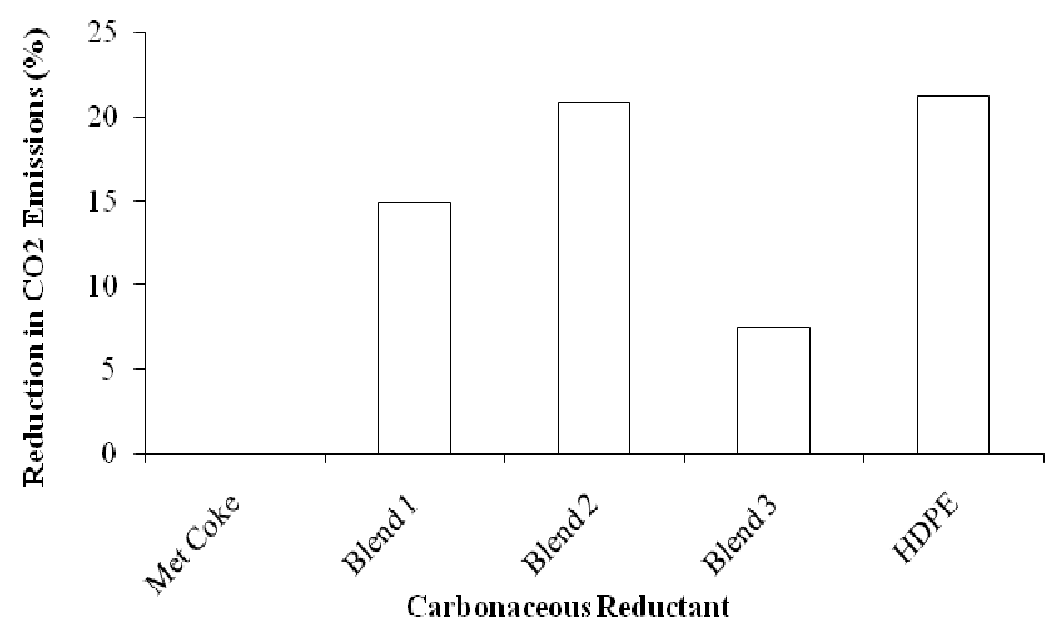

Fig. 11: Reduction in $\mathrm{CO}_{2}$ emissions over coke

sions with HDPE addition agrees with the observation by Matsuda et al. (2008) that it is possible to utilise waste plastics to produce metallic iron without generating $\mathrm{CO}_{2}$. Singh et al. (2010) observed a $6.5 \%$ reduction in $\mathrm{CO}_{2}$ emissions when coal was fired with $25 \% \mathrm{HDPE}$ (measured in terms of thermal energy). They attributed this to the higher heating value of HDPE $(46.2 \mathrm{MJ} / \mathrm{kg})$ as compared with that of coal.

\section{CONCLUSIONS}

A laboratory investigation has been conducted on the utilisation of HDPE and its blends with coke as reducing and carburising agents for the production of metallic iron from iron oxide.

The major findings of this investigation are:

(1) HDPE along with its blends with coke could be used effectively as reducing and carburising agents in iron oxide reduction.

(2) Blending of coke with HDPE resulted in:

- Significant improvements in the time re- quired for complete reduction of iron oxide (from 600s for coke to 330s for blends 1 and 2).

- Improved carburisation of the reduced metal.

- Reduction in $\mathrm{CO}_{2}$ emissions (over $20 \%$ decrease).

\section{REFERENCES}

Biswas, A. K. (1981). Principles of Blast Furnace Ironmaking. Cootha Publishing House, Brisbane, Australia

Dankwah, J. R. and Koshy P. (2013). "Production of Metallic Iron from Iron Oxide $\left(\mathrm{Fe}_{2} \mathrm{O}_{3}\right)$ using End-of-Life Rubber Tyre and its Blends with Metallurgical Coke as Reductants". International Journal of Engineering Research in Africa, 10:1-12.doi:10.4028/ www.scientific.net/JERA.10. 1

Dankwah, J. R. and Koshy P. (2013). "Reduction of $\mathrm{FeO}$ in EAF Steelmaking Slag by Blends of Metallurgical Coke and End-ofLife Polypropylene". High Temperature 
87

\section{Dankwah and Koshy}

Materials and Processes, 33(2): 107-114

Dankwah, J. R., Koshy, P. and Sahajwalla, V. H. (2013). "Reduction of FeO in EAF Steelmaking Slag by Blends of Metallurgical Coke and End-of-Life Polyethylene Terephthalate". Ironmaking and Steelmaking, DOI: 10.1179/1743281213Y.0000000125

Dankwah, J. R., Koshy, P., O'Kane, P. and Sahajwalla, V. (2012). "Reduction of $\mathrm{FeO}$ in EAF steelmaking slag by metallurgical coke and end-of-life rubber tyre". Steel Research. International, 83(8): 766-774

Donskoi, E., McElwain, D. L. S. and Wibberly, L. J. (2003). "Estimation and modelling of parameters for direct reduction in iron ore/ coal composites: Part II. Kinetic parameters". Metall. Mater. Trans. B, 34B: 255-266

Fruehan, R. J. (1973a). "The rate of carburisation on iron in $\mathrm{CO}-\mathrm{H}_{2}$ atmospheres: Part I. Effect of temperature and $\mathrm{CO}$ and $\mathrm{H}_{2-}$ pressures". Metallurgical Transactions, 4:2123-2127

Fruehan, R. J. (1973b). "The rate of carburisation of iron in $\mathrm{CO}-\mathrm{H}_{2}$ atmospheres: Part II. Effect of $\mathrm{H}_{2} \mathrm{O}$ and $\mathrm{H}_{2} \mathrm{~S}$ ", Metallurgical. Transactions, 4 : 2129-2132

Jones, J. (2007). "Utilisation of pig iron in the electric arc furnace". An International Pig Iron Association Technical Report

Karabelchtchikova, O. (1997). "Fundamentals of mass transfer in gas carburising". PhD. Thesis, Worcester Polytechnic Institute, New England, USA

Kaspersma, J. H. and Shay, R. H. (1980). "A model for carbon transfer in gas-phase carburisation of steel". J. Heat Treating, 1(4): 2128 .

Kikuchi, S., Ito, S., Kobayashi, I., Tsuge, O. and Tokuda, K. (2010). "ITmk $3{ }^{\circledR}$ process"

\section{Kobelco Technology Review, 29:77-84}

Matsuda, T., Hasegawa, M., Ikemura, A., Wakimoto, K. and Iwase, M. (2008). "Utilization of waste plastic for the production of metallic iron, hydrogen and carbon monoxide without generating carbon dioxide". ISIJ Int., 48: 1188-1196

Murakami, T. and Kasai, E. (2011). "Reduction mechanism of iron oxide-carbon composite with polyethylene at lower temperature". Journal of Iron and steel Institute of Japan International, 51: 9-13

Nishioka, K., Taniguchi, T., Ueki, Y., Ohno, K., Maeda, T. and Shimizu, M. (2007). "Gasification and reduction behaviour of plastics and iron ore mixtures by microwave heating". Journal of Iron and steel Institute of Japan International, 47(4):602-607

Ono-Nakazato, H., Yonezawa, T. and Usui, T. (2003). "Effect of water-gas shift reaction on reduction of iron oxide powder packed bed with H-CO mixtures". Journal of Iron and steel Institute of Japan International, 43: 1502-1511

Sawa, Y., Yamamoto, T., Takeda, K. and Itaya, H. (2001). "New coal-based process to produce high quality DRI for the EAF". Journal of Iron and steel Institute of Japan International, 41: S17-S21

Shi, J. Y., Donskoi, E., McElwain, D.L.S., and Wibberly, L. J. (2008). "Modelling novel coal based direct reduction process". Ironmaking and Steelmaking, 35: 3-13

Singh, S., Nimmo, W., Javed, M. T. and Williams, P. T. (2010). "Co-combustion of pulverised coal with waste plastic and tire rubber powders". Energy and Fuel, 25: 108-118

Sohn, I. and Fruehan, R. J. (2005). "The reduction of iron oxides by volatiles in a 
Effect of waste plastics addition on the reduction of iron oxide...

rotary hearth furnace process: Part I. The role

Met. Mat. Trans. B, 36B: 605-611 and kinetics of volatile reduction". 